\title{
The investigation of radiative heat transfer across molten mold flux film during the continuous casting of steels
}

\author{
D. W. Yoon ${ }^{1}$, J. W. Cho ${ }^{2}$ \& S. H. Kim ${ }^{1}$ \\ ${ }^{I}$ Department of Materials Science and Engineering, \\ Pohang University of Science and Technology, Republic of Korea \\ ${ }^{2}$ Graduate Institute of Ferrous Technology, \\ Pohang University of Science and Technology, Republic of Korea
}

\begin{abstract}
The non-uniform heat transfer through mold flux film induces breakout during continuous casting and surface defects on final casting steel products. It is significantly desirable to control the heat transfer rate from steel strand to copper mold during the casting process. Among the various modes of heat transfer through mold flux film, thermal radiation is believed to be dominant during initial solidification near meniscus. However, no systematic investigations have been carried out to understand radiative thermal performances, which consider the regulation of heat transfer behaviour through the glassy mold flux layer.

In this study, the thermal behaviour of commercial $\mathrm{CaO}-\mathrm{SiO}_{2}-\mathrm{Na}_{2} \mathrm{O}$ based mold fluxes has been investigated by using Fourier transform infrared spectroscopy (FT-IR) and Ultra violet-Visible spectrometer (UV-VIS) in the wavelength range of visible to near infrared to examine the thermal radiation transfer through glassy mold flux disk. Particularly, the effect of basicity and various $\mathrm{B}_{2} \mathrm{O}_{3}$ and $\mathrm{NiO}$ contents have been inspected. It is found that the heat flux density shows to be decreased by about $3 \%$, strongly affected by the addition of nickel oxide, which has a basicity of 0.95 in a slag system. The increase on absorption coefficients would not lead to an adverse effect on casting operations such as the lubrication of steels in the mold. Hence, it is only logical to optimize the chemical composition of mold fluxes to improve thermal radiative absorption performance between $1-5 \mu \mathrm{m}$ where the maximum radiative energy intensity is emitted in the region.

Keywords: continuous casting, heat transfer, mold flux, absorption coefficient.
\end{abstract}




\section{Introduction}

Mold flux acts as a lubricant to prevent tearing solidifying shell in continuous casting process. Mold powder existed in copper mold consists of solidus mold powder layer, sintered layer and slag pool by sensible heating from molten steel as shown in Fig. 1. A molten mold slag pool permeates into the channel between the copper mold and strand by oscillation of mold, forming a slag film which is composed of glassy state nearby solidifying shell, mixed crystalline and glassy layer beside copper mold. Each layer affects heat transfer through mold flux film by conductive and radiative thermal resistance [1]. Many previous studies suggested that another thermal resistance arising from air gap at interface of mold and mold flux film showed crucial effect on heat transfer in the mold [2-6]. Formation of surface defects on steel slabs is concentrically affected by the heat transfer in the mold during continuous casting. Heat flux density in initial solidification of steel near meniscus is higher than critical heat flux quantity, occurrence of surface cracks and breakouts are due to non-homogeneity growth of solidifying shell. Many efforts have been employed to investigate heat transfer near meniscus in the following approaches: i) conductive thermal resistance through crystalline phase, ii) radiative heat transfer through molten mold flux film. In order to regulate lattice thermal resistance, mold flux has desirable high basicity compounds which cause horizontal and vertical depressions on the slab by bad lubrication. Hence, thermal radiation is believed to be governable through mold flux film at initial solidification near meniscus. To control the heat flux in the mold, a reliable heat analysis is a significant topic to produce defect free steel products.

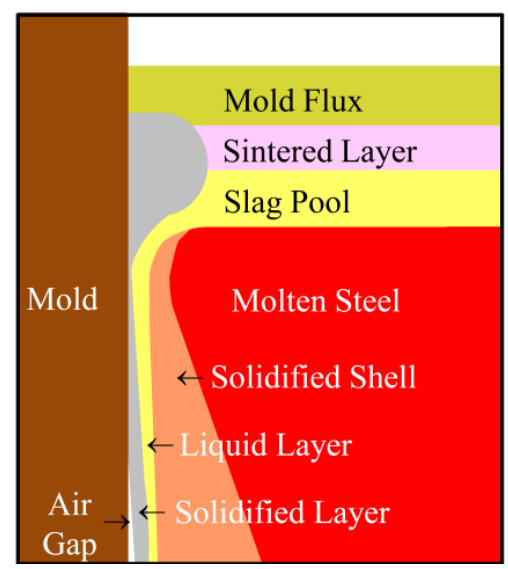

Figure 1: Schematic of mold in the continuous casting.

There are several attempts have been conducted to calculating radiative heat transfer through mold flux film with complex variables such as physical and chemical properties of mold flux, casting conditions in the mold. Nevertheless, 
these exertions the intricate occurrence are by far not thorougly comprehended yet and it is barely able to precisely predict the evaluation with regard to heat transfer of commercial mold fluxes. Susa et al. [7, 8] reported the absorption coefficient markedly dependent on the concentrations of transition metal oxides. For obtaining reliable heat flux data at high temperature, various mold fluxes which have broadly varying basicity and transition metal oxides are used in this study. Radiative heat flux is quantitatively measured by absorption coefficient and extinction coefficient of mold fluxes and diffusion approximation. Thermal radiation flux density through mold flux film was calculated by direct numerical analysis method.

\section{Experimental}

\subsection{Specimen preparation}

Commercial mold fluxes used in industrial continuous casting plants were selected as shown in Table 1. Mold fluxes containing $\mathrm{NiO}$ are based on M1 mold flux. Mold fluxes, were melted in graphite crucible into electric resistance furnace at $1603 \mathrm{~K}$ and burning off the skeleton materials, quenched on a copper mold, annealed to remove thermal stress for glassy specimens at $673 \mathrm{~K}$ for $1 \mathrm{~h}$. The glassy ample were cut and polished a thin disc type of $15 \mathrm{~mm}$ in diameter and $5-30 \mathrm{~mm}$ in thickness.

Table 1: Chemical composition of mold fluxes (mass \%).

\begin{tabular}{|c|c|c|c|c|c|c|c|c|c|}
\hline & $\mathrm{SiO}_{2}$ & $\mathrm{CaO}$ & $\mathrm{MgO}$ & $\mathrm{Al}_{2} \mathrm{O}_{3}$ & $\mathrm{Fe}_{2} \mathrm{O}_{3}$ & $\mathrm{Na}_{2} \mathrm{O}$ & $\mathrm{F}$ & $\mathrm{B}_{2} \mathrm{O}_{3}$ & Basicity \\
\hline $\mathrm{L} 1$ & 45.8 & 34.3 & 0.7 & 4.8 & 0.7 & 7.2 & 6.7 & - & 0.75 \\
\hline $\mathrm{M} 1$ & 41.1 & 38.5 & 0.8 & 5 & 0.7 & 7.3 & 7 & - & 0.94 \\
\hline $\mathrm{M} 2$ & 35.6 & 35.8 & 0.9 & 4.3 & 0.3 & 6.1 & 5.9 & 6.5 & 0.96 \\
\hline $\mathrm{H} 1$ & 36.7 & 41.7 & 0.8 & 5.3 & 0.6 & 7.4 & 7.2 & - & 1.14 \\
\hline $\mathrm{H} 2$ & 33.4 & 44.8 & 0.8 & 5.4 & 0.5 & 7.6 & 7.6 & - & 1.34 \\
\hline
\end{tabular}

\subsection{Determining absorption coefficient}

Absorption coefficient was measured with ultraviolet and Fourier transformation-infrared ray spectrometry in the $0.3-5.0 \mu \mathrm{m}$, followed by the conversion process using Lambert-beer's law. Consider spectral radiation of intensity impinging normally on a layer of material thickness. As the radiation passes through the layer, its intensity is decreased by absorption and scattering. The extinction coefficient consists of two parts, an absorption coefficient and a scattering coefficient. For glassy specimen, scattering factor could be neglected in the extinction coefficient.

$$
\alpha_{\lambda}=-\left(\ln \frac{I_{\lambda}(l)}{I_{\lambda}(0)}\right) / l
$$


Equation (1) is known as Lambert-Beer's law. It shows that, as a consequence of the intensity in radiative heat transfer along a path is exponentially while it passes through an absorbing medium as shown in Fig. 2.

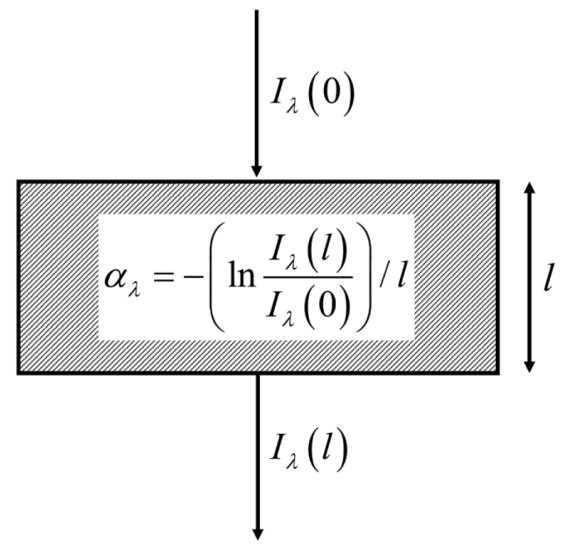

Figure 2: Schematic of absorption coefficient measurement.

\section{Results and discussion}

\subsection{Optical properties of mold fluxes}

According to Plank's law on the assumption of blackbody from solidifying shell, thermal radiation is intensively emitted in the range of $1.0-3.0 \mu \mathrm{m}$. Absorption coefficient of solidified glassy mold fluxes cannot arise differences of computing thermal radiation through molten flux layer in the mold [9-11]. Absorption coefficient calculated by Eq. (1) at room temperature for glassy mold flux films are given in Fig. 3. Mold fluxes show a steep inclination of absorption coefficient beyond of $4.5 \mu \mathrm{m}$ by stretching vibration of Si-O bonds. This result is consistent with the study by Cho et al. [1] who reported nearly transparent range below wavelength of $4.5 \mu \mathrm{m}$ for various mold slag systems. Absorption edges for the charge transfer band shows a marked move to higher wavelengths with increasing basicity from above results due to $\mathrm{Si}-\mathrm{O}$ bond stretching [12]. Comparing each absorption coefficient of mold fluxes, there is no different tendency of considered basicity and absorption results.

The occurrence sharp peak of M-2 sample in the range of $3.78-4.06 \mu \mathrm{m}$ is attributed by meta-borate ion [13].

The effect of $\mathrm{NiO}$ additions on the absorption coefficients of $\mathrm{Na}_{2} \mathrm{O}-\mathrm{CaO}-\mathrm{SiO}_{2}$ slags is shown in Fig 4. It can be seen that absorption coefficients increase in the $0.3-2.5 \mu \mathrm{m}$ region with increasing contents of nickel oxide. The spectra shows three absorption peaks at $0.45,0.95$, and $1.85 \mu \mathrm{m}$ by d-orbital transition [14]. By measured absorption coefficients, it is found that nickel oxide have proper thermal absorption in the region which is capable to control radiative heat flux density through mold slag film. 


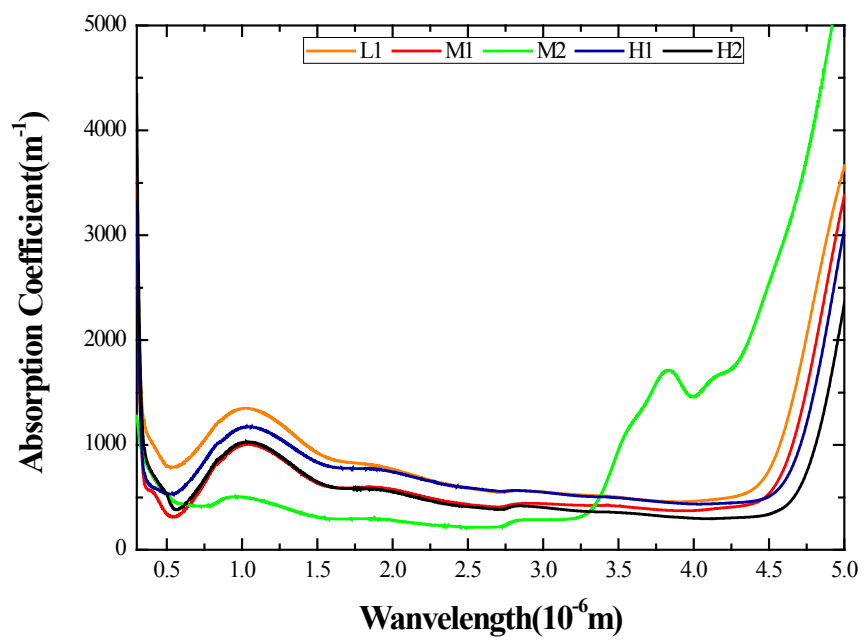

Figure 3: Absorption coefficients of mold fluxes.

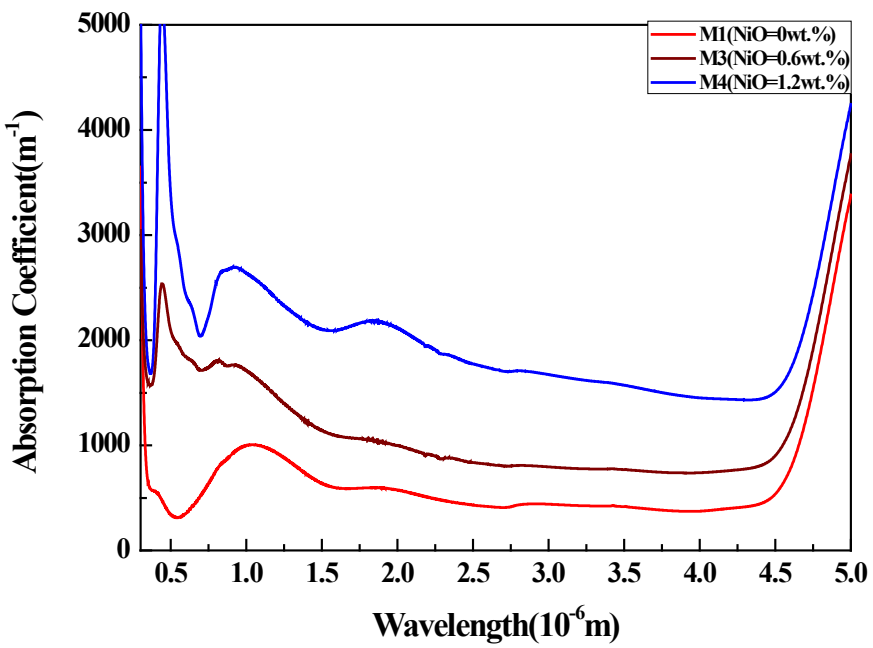

Figure 4: Absorption coefficient of Nickel oxide containing mold flux.

The ion refractivity of oxygen is calculated by subtracting the ion refractivity of the respective cations from the molar refractivity of slag, assuming that the ion refractivity of cations are constant, irrespective of slag as shown in Fig. 5. This molar refractivity of slag can be calculated using Lorentz-Lorenz equation. Increasing ion refractivity of oxygen causes the shift of absorption edge by electron donor power of oxygen ions in slag system. 


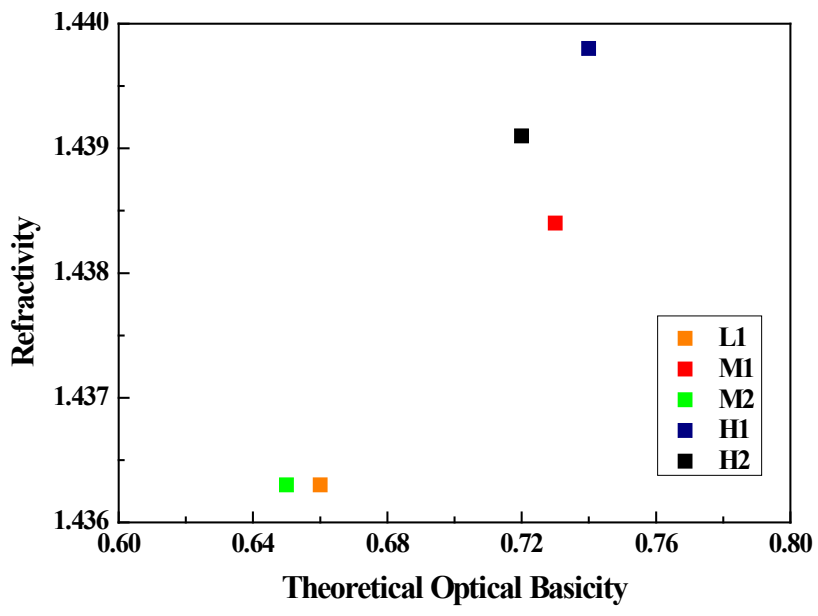

Figure 5: Effect of optical basicity on refractivity.

\subsection{Contribution of absorption coefficients and casting variables to total heat transfer}

Calculated total heat flux through mold flux film shows a decline with increasing flux film thickness as shown in Fig. 6. To investigate effects of casting conditions on heat transfer rate, conductive thermal diffusivity and interfacial thermal resistance, casting speed are used in this study.

Interfacial thermal resistance is assumed to be due to the air gap at the interface between copper mold and mold flux film in contact [15]. Decreasing interfacial thermal resistance causes the reduction of total heat flux in amounts of ca. 16-20\% with casting velocity at a flux thickness of $2 \mathrm{~mm}$ as shown in Fig. 6 (a) and (c). It can be seen that the increase of air gap arises from the deformation by solidification and crystallization of the flux film to induce reduction of heat transfer.

In the case of thermal diffusivity, several attempts have been made to obtain precise conductive thermal conductivity by indirect method such as laser flash method or hot wire method. Nevertheless, thermal conductivity for conduction remained unclear as yet. For this reason, thermal conductivity is assumed a constant value both laser flash $(1.73(\mathrm{~W} / \mathrm{m} \cdot \mathrm{K}))$ [1] and hot wire $(0.8(\mathrm{~W} / \mathrm{m} \cdot \mathrm{K}))$ [16] method by previous researchers. The calculated result from different conductive value shows strong influence on total thermal quantity about $c a$. 9-13\% in fixed flux thickness of $2 \mathrm{~mm}$ as shown in Fig. 6 (b) and (d).

The effect of casting speed on total heat transfer rate is computed with varied variable and shown in Fig. 6. The change of casting speed from 1 to $5 \mathrm{~m} / \mathrm{min}$ increase $c a$. 3-6\% of total heat flux with different thermal properties and condition at a flux thickness of $2 \mathrm{~mm}$. Concurrently, increment of casting speed decreases flux film thickness about $0.91 \mathrm{~mm}$. From this approach, increased velocity from 1 to $5 \mathrm{~m} / \mathrm{min}$ shows increasing $c a$. $35 \%$ of total heat flux through flux film. 


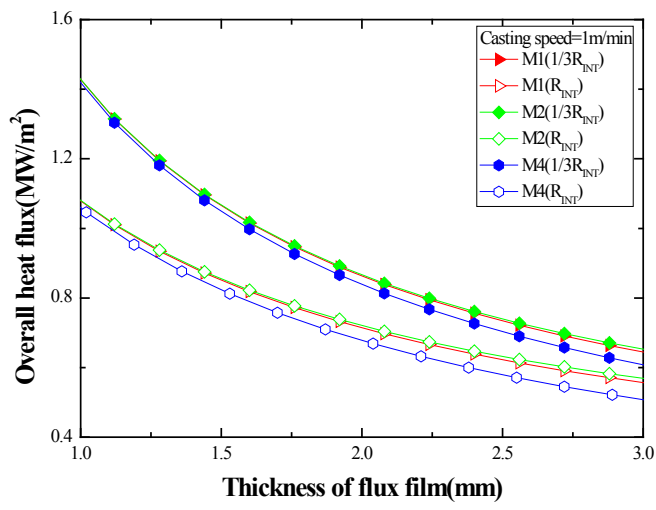

(a) Interfacial resistance at $\mathrm{V}_{\mathrm{c}}=1 \mathrm{~m} / \mathrm{min}$

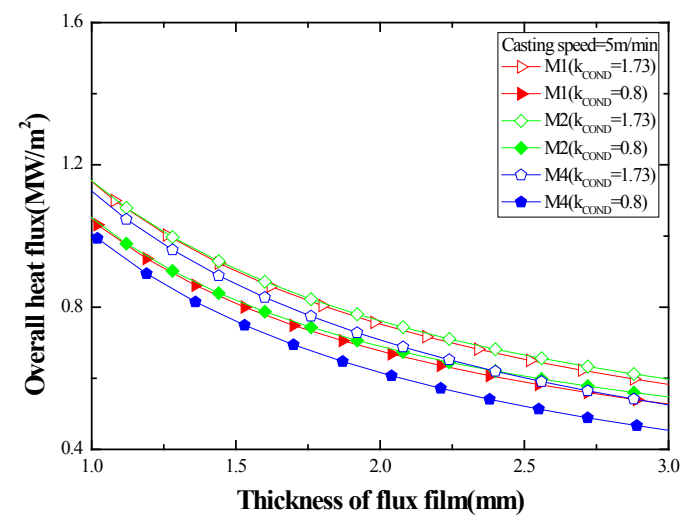

(b) Conductive thermal conductivity at $\mathrm{V}=\mathrm{lm} / \mathrm{min}$

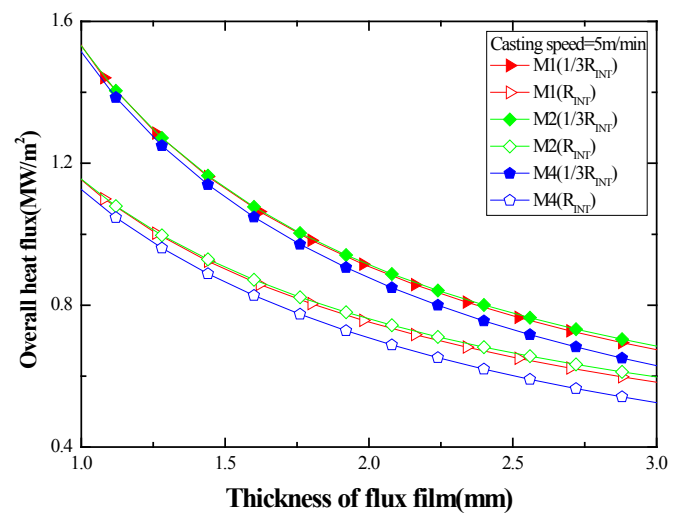

(c) Interfacial resistance at $\mathrm{Vc}=5 \mathrm{~m} / \mathrm{min}$

Figure 6: Overall heat transfer rate computed by absorption coefficients and casting variables. 


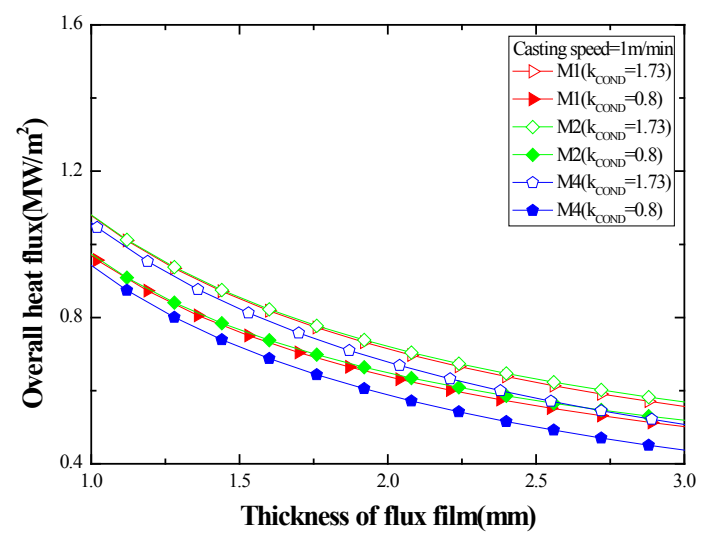

(d) Conductive thermal conductivity at $\mathrm{V}_{\mathrm{c}}=5 \mathrm{~m} / \mathrm{min}$

Figure 6: Continued.

With respect to the properties of mold fluxes, absorption coefficients are largely same for various mold fluxes [1]. However, mold fluxes which contain transition metal oxide have an impact on the radiative heat flux density as shown in Fig. 6. It is found that mold flux containing $\mathrm{NiO}$ decrease $c a$. $2-9 \%$ of overall heat flux compared with value of commercial mold flux at a flux thickness of $2 \mathrm{~mm}$.

Absorption coefficient of mold flux could control the total heat transfer through mold flux film in the mold near meniscus. Consequentially, selection of proper flux component for casting steel should not be intensively dependent on the optical properties but on the thermal performance as slow cooling which can be effectively achieved by transitional metal oxide mold flux.

\section{Conclusions}

Heat transfer rate across mold flux film of various mold fluxes in continuous casting mold has been investigated. The results are summarized as follows:

(1) Mold flux containing nickel oxide shows $c a$. 2-9\% of radiative heat flux smaller than commercial mold flux at a flux thickness of $2 \mathrm{~mm}$.

(2) Change of casting speed from 1 to $5 \mathrm{~m} / \mathrm{min}$ results in $c a .35 \%$ of increase in total heat transfer comparing with M1-mold flux.

(3) Increasing with conductive thermal conductivity of mold fluxes and interfacial thermal resistance induce decrease of $c a$. $9-20 \%$ of overall heat flux density from solidifying shell to copper mold.

\section{References}

[1] Cho, J.W., Emi, T., Shibata, H. \& Suzuki, M., Radiative heat transfer through mold flux film during initial soldification in continuous casting of steel. ISIJ International, 38(3), pp. 268, 1998. 
[2] Ohmiya, S., Tacke, K.H. \& Schwerdtfeger, K., Heat transfer through layers of casting fluxes. Ironmaking Steelmaking, 10(1), pp. 24, 1983.

[3] Cho, J.W., Emi, T., Shibata, H. \& Suzuki, M., Thermal resistance at the interface between mold flux film and mold for continuous casting of steels. ISIJ International, 38(5), pp. 440, 1998.

[4] Shibata, H., Kondo, K., Suzuki, M. \& Emi, T., Thermal resistance between solidifying steel shell and continuous casting mold with intervening flux film. ISIJ International, 36, S179, 1996.

[5] Watanabe, K., Suzuki, M., Murakami, K., Kondo, H., Miyamoto, A. \& Shiomi T., The effect of crystallization of mold powder on the heat transfer in continuous casting mold. Tetsu-to-Hagane, 83(2), pp. 115, 1997.

[6] Yamauchi, A., Sorimachi, K., Sakuraya, T. \& Fuhii, T., Heat transfer between mold and slab through mold flux film in continuous casting of steel. Tetsu-to-Hagane, 79(2), pp. 167, 1993.

[7] Susa, M., Nagata, K. \& Mills, K.C., Absorption coefficients and refractive indices of synthetic glassy slags containing transition metal oxides. Ironmaking Steelmaking, 20(5), pp. 372, 1993.

[8] Susa, M., Li, F. \& Nagata, K., Determination of refractive index and absorption coefficient of iron-oxide-bearing slags. Metallurgical and Materials Transaction B, 23B, pp. 334, 1992.

[9] Kusabiraki, K. \& Shiraishi, Y., Infrared emission spectra of molten alkaline metal silicates, Journal of the Japan Institute of Metals, 45(3), pp. 250, 1981.

[10] Kusabiraki, K. \& Shiraishi, Y., On the infrared emission spectra of the molten $\mathrm{Na}_{2} \mathrm{O}-\mathrm{Al}_{2} \mathrm{O}_{3}-\mathrm{SiO}_{2}$ system. Journal of the Japan Institute of Metals, 45(9), pp. 888, 1981.

[11] Kusabiraki, K. \& Shiraishi, Y., On the infrared emission spectra of molten silicates in the system $\mathrm{Na}_{2} \mathrm{O}-\mathrm{TiO}_{2}-\mathrm{SiO}_{2}$, Journal of the Japan Institute of Metals, 45(3), pp. 259, 1981.

[12] Hayashi, M., Susa, M., Oki, T. \& Nagata, K., Shift of the absorption edge for the charge transfer band in slags containing iron oxides. ISIJ International, 37(2), pp. 126, 1997.

[13] Hisatsune, I.C. \& Suarez, N.H., Infrared spectra of metaborate monomer and trimer ions. Inorganic chemistry, 3(2), pp. 171, 1964.

[14] Berkes, J. S. \& White, W.B., Optical spectra of nickel in alkali tetraborate glasses. Physics and Chemistry of Glasses, 7(6), pp. 191, 1966.

[15] Bagha, S., Machingawuta, N.C.\& Grieveson, P., Heat transfer simulation for continuous casting. Proc. of the $3^{\text {rd }}$ Int. Conf. on Molten Slags, Fluxes and Salts, ISS, Glasgow, 235, 1988.

[16] Kang, Y. \& Morita, K., Thermal conductivity of the $\mathrm{CaO}-\mathrm{Al}_{2} \mathrm{O}_{3}-\mathrm{SiO}_{2}$ system, ISIJ International, 46, pp. 421, 2006. 